\title{
VoxSanguinis
}

\section{The Treatment of Patients with Autoimmune Thrombocytopenia with Intravenous IgG-Anti-D}

\section{C.P. Engelfriet \\ H.W. Reesink}

Salama et al. [1] noticed that in patients with autoimmune thrombocytopenia (AITP) treated with high-dose i.v. Ig, the red cells became weakly sensitized with IgG antibodies, present in the i.v. Ig preparation. They concluded that the effect of i.v. Ig on the platelet count is due to a competition between sensitized red cells and platelets sensitized with auto-antibodies, for Fc-receptors $(\mathrm{FcR})$ on splenic macrophages. This observation was the basis of their treatment of patients with AITP with i.v. anti-D IgG. Since the first publication of Salama et al. [2] on the subject, many patients have been treated in several centres. There is controversy concerning the question whether the effect of i.v. anti-D $\mathrm{IgG}$ is indeed due to a competition between sensitized red cells and sensitized platelets for FcR and therefore to the RhD antibodies themselves, or to other factors, also present in the anti-D preparation. This question is interesting from a theoretical but also from a practical point of view. There is a general shortage of anti-D Ig for immunoprophylaxis in D-negative women. If not the anti-D but other factors are responsible for the effect in AITP, anti-D Ig should not be used to treat patients with this disease. These considerations led us to devote an International Forum to this subject. The questions listed below were sent to 18 experts of whom 7 have contributed to the Forum.

\section{Questions}

(1) Do you, or your colleagues, treat patients with AITP with i.v. anti-D Ig or have you done so in the past?

(2) If so, what have the results of this treatment been?

(3) If treatment with anti-D causes an increase in the platelet count

(a) do you think that this effect is due to a competition between anti-D IgG sensitized red cells and auto-antibody-sensitized platelets for FcR on macrophages? If so, how do you explain the simultaneous, often severe, destruction of red cells by IgG warm auto-antibodies and of platelets by auto-antibodies in Evans' syndrome?

(b) do you think that any effect on the platelet count is not due to anti-D but, e.g, to other antibodies present in the anti-D preparation?

(c) do you have experience with anti-D treatment of Rh-D-negative patients with AITP?

(d) do you have experience with anti-D treatment of patients with IgA platelet autoantibodies?

\section{Comments}

As could be expected, some of those who contributed to the Forum believe that the effect of i.v. anti-D Ig is indeed due to competition for FcR as outlined above or that in any case the patients' red cells must become sensitized with IgG antibodies for an effect (see
Godeau and Bierling) and thus that the $\mathrm{RhD}$ antibodies themselves are responsible. Others, however, think that other factors, also present in the anti-D preparation, such as IgG polymers and, or HLA antibodies (see Neppert; Panzer et al.) are involved.

Arguments in favour of $\mathrm{RhD}$ antibodies themselves being responsible are as follows: the most important argument is that anti-D Ig has no effect in D-negative patients, but is this proven? From the literature it appears that in total $6 \mathrm{D}$-negative patients have been treated with anti-D Ig. In 4 there was no response, [3-5] but in 2 the effect was as good as in D-positive patients [6,7]. The D-negative patient treated by Broughton et al. [5] was c-positive but did not react to a large dose of IgG anti-c either. One D-positive, cnegative patient treated by Oksenshendler et al. [8] reacted to anti-D Ig but not to plasma containing IgG anti-c, which had been effective in 3 c-positive patients. However, since it is unknown why in up to $30 \%$ of D-positive patients anti-D Ig has no effect [see, e.g., ref. 9 and 10], the results in this single patient do not seem to be greatly significant. Apart from the fact that some D-negative patients have been treated successfully with anti-D Ig, clearly, since so many D-positive patients do not react, far more D-negative patients need to be treated before it can be concluded that anti-D Ig is only reactive in D-positive patients.

Another important argument is that antiD Ig is not, or much less, effective in splenectomized patients. Not only has this not been

\begin{tabular}{ll}
\hline KARGER & (c) 1999 S. Karger AG, Basel \\
Fax +41 61 306 12 34 & 0042-9007/99/0764-0250 \$17.50/0 \\
$\begin{array}{l}\text { E-Mail karger@ karger.ch } \\
\text { www.karger.com }\end{array}$ & Accessible online at: \\
& http://BioMedNet.com/karger
\end{tabular}


found by all those who treated such patients, but it should also be realized that patients with AITP who remain severely thrombocytopenic after splenectomy are a selected group in whom sensitized platelets are destroyed outside the spleen. This implies a very strong sensitization by auto-antibody and inhibiting the destruction of such platelets is probably much more difficult, whatever the inhibiting mechanisms may be. Moreover, in some of these patients the autoantibodies may be IgA, which adheres to a different FcR and which, as red cell auto-antibodies, are known to cause severe haemolysis or in some the auto-antibodies might be complement binding.

The following arguments plead against a direct role of anti-D: 5 patients with AITP were successfully treated by Smith et al. [11] with the non-specific fraction of anti-D Ig and its effect was ascribed to $\mathrm{IgG}$ polymers in the preparation.

In explaining the effect of anti-D, it has been assumed that the affinity for FcR of red cells sensitized with $\mathrm{IgG}$ is greater than that of platelets sensitized with IgG auto-antibodies. Low numbers of $\operatorname{IgG}$ auto-antibodies, below the detection level of the platelet immunofluorescence test (PIFT) have been found to induce destruction of platelets [12] and it is well known that low concentrations of maternal IgG auto-antibodies, equally below the detection level of the PIFT, can cause severe thrombocytopenia in the fetus and newborn, even though the macrophages are still immature. This points to a strong rather than a weak affinity of sensitized platelets for FcR.

In Evans' syndrome, often severe, autoimmune haemolytic anaemia (AIHA) occurs together with, often severe, AITP. The responsible red cell auto-antibodies are, like anti-D IgG, non-complement-binding IgG antibodies. The destruction of red cells sensitized with such antibodies obviously does not prevent the destruction of sensitized platelets in these patients. Although, as one of the contributors mentions (see Bussel), AIHA and ITP do not always occur at the same time in these patients, they frequently do. We even observed a patient in whom AIHA, AITP and autoimmune granulocytopenia with IgG antibodies, occurred together.

Human monoclonal anti-D IgG, capable of causing red cell destruction, failed to have any effect in D-positive AITP patients [13]. Presumably there are few if any $\operatorname{IgG}$ polymers and certainly no HLA antibodies in such a preparation.
Finally, as mentioned, 2 of 6 D-negative patients were successfully treated with antiD Ig.

It seems questionable whether the observation by Salama et al. [1] that the red cells of patients treated with i.v. Ig become sensitized with IgG antibodies warranted their conclusion that the effect of i.v. Ig is due to red cell antibodies present in the preparation. Although some i.v. Ig preparations have been found to contain traces of anti-D, the bulk of the $\mathrm{IgG}$ antibodies is IgG anti-A and -B. Thus the red cells of group $\mathrm{O}$ patients should be expected to become only weakly sensitized, if at all. Are there any indications that i.v. Ig is less effective in group $\mathrm{O}$ patients?

In conclusion, we think that the case for the $\mathrm{RhD}$ antibodies themselves being responsible for the effect of i.v. anti-D Ig is weak. It seems likely that other factors are at least also involved. Since it has been shown, in a large prospective study [14] that i.v. Ig is more effective than anti-D in the treatment of AITP and not less effective than anti-D in children [15], we feel, like several of the contributors to this Forum that anti-D Ig should not be used to treat AITP, except perhaps in very special circumstances.

\section{References}

1 Salama A, Mueller-Eckhardt C, Kiefel V: Effect of intravenous immunoglobulin in immune thrombocytopenia. Lancet 1983;ii:193195.

2 Salama A, Kiefel V, Amberg R, Mueller-Eckhardt C: Treatment of autoimmune thrombocytopenic purpura with rhesus antibodies (anti$\mathrm{Rh}_{\mathrm{o}}$ (D)). Blut 1984;49:29-35.

3 Salama A, Kiefel V, Mueller-Eckhardt C: Effect of IgG anti- $\mathrm{Rh}_{\mathrm{o}}$ (D) in adult patients with chronic autoimmune thrombocytopenia. Am J Hematol 1986;22:241-250.

4 Bierling P, Oksenshendler E, Habibi B, et al: Anti-rhesus antibodies as treatment for HIVrelated immune thrombocytopenia. Am J Med 1987;106:733-734.

5 Broughton BJ, Chakraverty R, Baglin TP, et al: The treatment of chronic idiopathic thrombocytopenia with anti-D $\left(\mathrm{Rh}_{\mathrm{o}}\right)$ immunoglobulin: Its effectiveness, safety and mechanism of action. Clin Lab Hematol 1988;10:275-284.

6 Moise KJ, Cano LE, Sala DJ: Resolution of severe thrombocytopenia in a pregnant patient with rhesus-negative blood with autoimmune thrombocytopenic purpura after intravenous rhesus immune globulin. Am J Obstet Gynecol 1990;162:1237-1238.

7 Vizcaino G, Diez-Ewald M, Arteaga-Vizcaino E: Use of anti-D (Rh) IgG or intramuscular polyvalent human immunoglobulin in the treatment of chronic autoimmune thrombocytopenic purpura. Invest Clin 1992;33:165-174.
8 Oksenhendler E, Bierling $\mathrm{P}$, Brossard Y, Schenmetzler C, Girard PM, Seligmann M, Clauvel JP: Anti-Rh immunoglobulin therapy for human immunodeficiency virus-related immune thrombocytopenic purpura. Blood 1988;71:1499-1502.

9 Freiberg A, Manger D: Efficacy, safety, and dose response of intravenous anti-D immune globulin (Wim $\mathrm{Rh}_{\mathrm{o}} \mathrm{SDF}$ ) (in the treatment of idiopathic thrombocytopenic purpura in children. Semin Hematol 1998;35(1 suppl 1):2327.

10 Scaradavou A, Bussel JB: Clinical experience with anti-D in the treatment of idiopathic thrombocytopenic purpura. Semin Hematol 1998;35(1 suppl 1):52-57.

11 Smith NA, Chakraverty RK, Broughton BJ: The successful treatment of idiopathic thrombocytopenic purpura with the low dose, nonspecific IgG component of anti-D immunoglobulin. Clin Lab Heatol 1998;12:131-136.

12 Tijhuis GJ, Klaassen RJL, Modderman PW, et al.: Quantification of platelet-bound immunoglobulins of different class and subclass using radiolabelled monoclonal antibodies: Assay conditions and applications. Br J Haematol 1991;77:93-101.

13 Godeau B, Oksenhendler E, Bartholeyns J, et al.: Treatment of chronic autoimmune thrombocytopenic purpura with monoclonal anti-D, Transfusion 1996;36:328-330.

14 McMillan J, Wang E, Milner R, et al.: Randomized trial of intravenous immunoglobulins, intravenous anti-D and oral prednison in childhood acute immune thrombocytopenic purpura. Lancet 1994;344:703-707.

15 Andrew M, Blanchette VS, Adams M, et al.: A multicenter study of the treatment of childhood chronic idiopathic thrombocytopenic purpura with anti-D. J Pediatr 1992;120:522-527.

Prof. Dr. C.P. Engelfriet

Central Laboratory of The Netherlands

Red Cross Blood Transfusion Service PO Box 9137

NL-1006 AC Amsterdam (The Netherlands)

H.W. Reesink, MD, PhD

Red Cross Blood Bank Amsterdam PO Box 9137

NL-1006 AC Amsterdam (The Netherlands) 


\section{James Bussel}

The New York Hospital-Cornell Medical Center has had extensive experience with the use of intravenous (i.v.) anti-D for the treatment of immune (idiopathic) thrombocytopenia (AITP). Our series of 261 not splenectomized patients initially treated by the end of 1994 was recently published [1]. The salient results of treatment were that the mean platelet increase was $>40,000 / \mu l$ in every patient group and that the response rate was $>60 \%$ in every group with an overall response rate of $72 \%$. Splenectomized patients did not respond as well.

The increase in the platelet count with i.v. anti-D was slower and to a lower peak level compared with i.v. Ig [2]. More recently, we compared $75 \mu \mathrm{g} / \mathrm{kg}$ with $50 \mu \mathrm{g} / \mathrm{kg}$ of i.v. antiD [3]. Preliminary results suggest not only that the platelet count increases to a significantly higher level at the higher dosc but also that the rate of platelet increase is faster at the higher dose. There is a significant platelet increase in most patients within $24 \mathrm{~h}$. We have therefore begun to treat children with acute AITP at diagnosis with $75 \mu \mathrm{g} / \mathrm{kg}$ of i.v. antiD. So far, in 5/5 patients evaluated the day after treatment, we have seen increases of $\geq 30,000 / \mathrm{mm}^{3}$. A greater degree of hemolysis at the higher dose appears to be evident only at 2 weeks after treatment rather than 1 week.

Rh-negative patients do not respond to treatment with anti-D. This has been our experience in 2 patients who were inadvertently treated with anti-D despite being Rh-negative. The most decisive evidence has been provided by Oksenshendler et al. [4], in which $3 \mathrm{Rh}$-negative patients did not respond to i.v. anti-D and subsequently responded to the infusion of plasma containing anti-c. We therefore believe that the mechanism of effect of i.v. anti-D requires coating of red cells with antibody, resulting in competition with antibody-coated platelets for Fc-receptors ( $\mathrm{FcR})$ on macrophages. Additional mechanisms of effect are not well understood but seem to be dependent upon interaction of antibody-coated red cells with cell associated FcR.

We reported our experience in Evans' syndrome in which a patient with a positive direct Coombs and severe chronic a ITP had a dramatic increase in platelet count to $400,000 / \mathrm{mm}^{3}$ coincident with the onset of autoimmune hemolysis [9]. A clear majority of patients with Evans' syndrome do not have simultaneous ongoing hemolysis and thrombocytopenia. We believe that is because the ef- fect of autoimmune hemolysis is similar to the effect of i.v. anti-D once the immune hemolysis is initiated, the platelet will increase. In the uncommon situations where both cytopenias are clinically active at the same time, there is presumably either intravascular lysis or inhibition of marrow production of one or other cell type. Wang [6] first reported transient marrow hypoplasia in patients with Evans' syndrome.

The selectivity of the anti-D effect in Rhpositive patients seems to guarantee that the effect of anti-D is in fact due to the anti-D. There is no evidence for the presence of other high-titer antibodies, i.e., anti-Fc-receptor antibodies, in anti-D per se. It is possible that anti-idiotypes to anti-D may be important, but presumably only as part of an immune complex with the anti-D itself.

Platelet antibody studies have not been shown to be meaningful in the management of AITP [7]. We have had no experience comparing the anti-D response with different types of platelet antibody patterns.

\section{References}

1 Scaradavou A, Woo B, Woloski BMR, et al: Intravenous anti-D treatment of immune thrombocytopenic purpura. Experience in 272 patients. Blood 1997;89:2689-2700.

2 Bussel JB, Graziano JN, Kimberly RP, Pahwa $\mathrm{S}$, Aledort LM: Intravenous anti-D treatment of immune thrombocytopenic purpura: Analysis of efficacy, toxicity and mechanism of effect. Blood 1991;77:1884-1893.

3 Bussel JB, Novoa M, Shine E, Woloski BMR: In patients with ITP, does $75 \mu \mathrm{g} / \mathrm{kg}$ of IV anti$D$ increase the platelet count faster than $50 \mu \mathrm{g} / \mathrm{kg}$ ? (abstract) Blood 1997;90.

4 Oksenhendler E, Bierling P, Brossard Y, Schenmetzler C, Girard PM, Seligmann M, Clauvel JP: Anti-Rh immunoglobulin therapy for human immunodeficiency virus-related idiopathic thrombocytopenic purpura. Blood 1988;71:1499-1502.

5 Scaradavou A, Bussel J: Evans' syndrome. Results of a pilot study utilizing a multiagent treatment protocol. J Pediatr Hematol Oncol 1995;17:290-295.

6 Wang WC: Evans syndrome in childhood; Pathophysiology, clinical course, and treatment. Am J Pediatr Hematol Oncol 1998;10: 330-338.

7 George JN, Woolf SH, Raskob GE, et al: Idiopathic thrombocytopenic purpura: A practice guideline developed by explicit methods for the American Society of Hematology. Blood 1996;88:3-40.
J. Bussel

The New York Hospital

Cornell Medical Center

Department of Pediatrics

525 East 60th Street

New York, NY 10021 (USA)

\section{Bertrand Godeau \\ Philippe Bierling}

\section{Questions 1 and 2}

In the eighties, we frequently treated patients with severe human immunodeficiency virus (HIV)-related immune thrombocytopenic purpura (AITP) with anti-D. The results obtained in $14 \mathrm{Rh}$-positive HIV-infected patients who received $12-25 \mu \mathrm{g} / \mathrm{kg}$ i.v. of IgG anti-D on 2 consecutive days have previously been reported [1]. A significant platelet rise above $50 \times 10^{9} / 1$ was obtained in 9 cases. Repeated boosters were performed in 6 cases and were transiently effective in all cases. Therapy was well tolerated and no patient had severe haemolysis. However, we now use polyclonal anti-D Ig only occasionally because of its limited supply; stocks of anti-D for the prevention of Rh haemolytic disease might be depleted by the frequent use of this agent in patients with AITP. Furthermore, the exact indication of anti-D in the treatment of adults with AITP is not easy to determine. Thus, as the platelet response with anti-D is slower than with i.v. Ig, occurring at least 2 days later [2], the use of i.v. Ig (or high-dose i.v. methylprednisolone [3]) is encouraged in our institution in emergency situations. On the other hand, for patients with chronic AITP, the usually transient effect of the treatment (relapse occurs in most responders within 20-30 days) argues against its use. Finally, in our view, anti-D is only indicated in a few selected adult patients with life-threatening chronic AITP in whom other treatments fail or are contra-indicated.

\section{Question 3}

The postulated mechanism of action of anti-D in patients with AITP is based on competitive inhibition of the reticuloendothelial system by sequestration of IgG-coated autologous RBCs, leading to decreased destruction of auto-antibody-sensitized platelets. However, several data suggest that anti-D preparations also act through other im- 
munoregulatory effects, which could be due to other antibodies, such as specific Fc-receptor $(\mathrm{FcR})$ antibodies and/or HLA antibodies present in the anti-D preparation. Bussel et al. [2] demonstrated an inverse relation after anti-D injection between the increase in the expression of FcR I on circulating monocytes and platelet count, and suggested that this effect may represent an immunomodulatory effect of anti-D preparations not directly related to RBC antibody-coating since circulating monocytes are not known to phagocytose antibody-coated RBCs in vivo. Other arguments for the idea that anti-D Ig may act through immunomodulatory effects could be found in the time lag between anti-D administration and the increase in platelet count (usually 2-3 days later) and the absence of a correlation between the dose of polyclonal anti-D administered, the amount of RBC-associated $\mathrm{IgG}$, the degree of haemolysis, and the platelet increment $[1,2]$. The poor response we observed with a monoclonal anti$\mathrm{D}$ also points to a possible additional role of Igs other than anti-D that are present only in human polyclonal anti-D preparations [4]. Indeed, no or little platelet count increment was observed in 6 of 7 AITP patients we treated, while binding of monoclonal anti-D to RBCs was demonstrated in all patients at a ratio higher than that observed in AITP patients successfully treated with polyclonal anti-D. However, the immunoregulatory effects induced by anti-D preparations alone cannot, in our view, explain the effect of polyclonal anti-D preparations, since we clearly demonstrated that anti-D or anti-c polyclonal preparations cause transient platelet increment, respectively, in D-positive or c-positive patients with AITP but not in Dnegative or c-negative patients $[1,5]$ : our observations provide clear evidence that the effect of anti-Rh preparations requires an interaction between $\mathrm{RBCs}$ and the specific anti RBC antibodies.

\section{Question 3}

We have no experience with anti-D treatment of patients with IgA platelet auto-antibodies.

\section{References}

1 Oksenhendler E, Bierling P, Brossard Y, Schenmetzler C, Girard PM, Seligmann M, Clauvel JP: Anti-Rh immunoglobulin therapy for human immunodeficiency virus-related immune thrombocytopenic purpura. Blood 1988;71:1499-1502.
2 Bussel J, Graziano JN, Kimberly RP, Pahwa S, Aledort LM: Intravenous anti-D treatment of immune thrombocytopenic purpura: Analysis of efficacy, toxicity, and mechanism of effect. Blood 1991;77:1884-1893.

3 Godeau B, Zini JM, Schaeffer A, Bierling P: High-dose methylprednisolone is an alternative treatment for adults with autoimmune thrombocytopenic purpura refractory to intravenous immunoglobulins and oral corticosteroids. Am J Hematol 1995;48:282-284.

4 Godeau B, Oksenshendler E, Bartholeyns J, Leaute JB, Duedari N, Schaeffer A, Bierling P: Treatment of chronic autoimmune thrombocytopenic purpura with monoclonal anti-D. Transfusion 1996;36:328-330.

5 Bierling P, Karianakis G, Duedari N, Desain C, Oksenhendler E, Habibi B, Brossard Y: Anti-rhesus antibodies, immune thrombocytopenia, and human immunodeficiency virus infection. Ann Intern Med 1987;106:773-774.

Dr. Bertrand Godeau

Service de Médecine Interne I

Hôpital Henri-Mondor

51 avenue de-Lattre-de-Tassigny

F-94 000 Créteil (France)

\section{Simon Panzer \\ Eva Renate Grümayer-Panzer Wolfgang Richard Mayr}

It has been suggested that blockade of the monocyte/macrophage system in the spleen can induce an increase of platelet count in patients with idiopathic autoimmune thrombocytopenia (AITP). This assumption is based on the observation that in these patients increased sequestation occurs primarily in the spleen, and that upon blockade of the Fc-receptor $(\mathrm{FcR})$ of the monocyte/macrophage system, platelet count increases. In 1983, Salama et al. [1] reported that treatment of AITP with i.v. IgG results in a positive direct antiglobulin test (DAT). The authors assumed that red cells coated with antibodies contained in the i.v. IgG compete with antibodycoated platelets for FcR on cells of the monocyte/macrophage system. This hypothesis was substantiated by the observed platelet increase after induction of a positive DAT by anti- $\mathrm{Rh}_{\mathrm{o}}$ (D) in $\mathrm{Rh}_{\mathrm{o}}$ (D)-positive individuals. Following the initial report, various investigators have been able to show that anti- $\mathrm{Rh}_{0}$ (D) is effective in treating AITP, but its effica- cy to restore the peripheral platelet count is less than that of i.v. $\operatorname{IgG}$ [2]. The effect is not related to the degree of anti- $\mathrm{Rh}_{\mathrm{o}}$ (D) induced haemolysis. Thus, it can be assumed that it is not the anti- $\mathrm{Rh}_{\mathrm{o}}$ (D) activity alone that is responsible for the effect of this treatment on platelets in AITP.

Clonality of the antibodies and MHC complex-blocking reagents in the preparations are our favorite candidates, for explaining the effects that lead to the increase of platelet count after administration of anti- $\mathrm{Rh}_{0}$ (D). Whether or not the efficacy of anti- $\mathrm{Rh}_{0}$ (D) depends on its reaction with $\mathrm{Rh}_{\mathrm{o}}$ (D)-positive red cells is controversial, and has not been tested in our patient population. We consider anti- $\mathrm{Rh}_{\mathrm{o}}$ (D) administration to patients with chronic AITP as a last option of treatment, particularly in physically very active children with platelet counts less than $30 \times 10^{9} / 1$, if other therapeutic measurements are either not effective or the effect of i.v. IgG seems to wear out [3]. Thus, in view of the shortage of anti- $\mathrm{Rh}_{\mathrm{o}}(\mathrm{D})$, we consider its preferential use for the established indication of prevention of $\mathrm{Rh}$ immunization, and not for the treatment of AITP, which is a rather benign disease and in most cases can successfully be controlled by other therapeutic regimens.

\section{References}

1 Salama A, Mueller-Eckhardt C, Kiefel V: Effect of intravenous immunoglobulin in immune thrombocytopenia. Competitive inhibition of reticuloendothelial system function by sequestration of autologous red blood cells. Lancet 1983;ii:193-195.

2 Panzer S, Grümayer ER, Haas OA, Niessner $\mathrm{H}$, Graninger W: Efficacy of rhesus antibodies (anti- $\left.\mathrm{Rh}_{\mathrm{o}}(\mathrm{D})\right)$ in autoimmune thrombocytopenia: Correlation with response to high-dose $\mathrm{IgG}$ and the degree of haemolysis. Blut 1986; 52:117-121.

3 Grümayer ER, Haas OA, Panzer S, Gadner H: ITP in childhood: Difficulties in the individual treatment. Klin Pädiatrie 1986;198:414-417.

Simon Panzer

Eva Renate Grümayer-Panzer

Wolfgang Richard Mayr

Clinic for Blood Group Serology

University of Vienna

Währinger Gürtel 18-20

A-1090 Vienna (Austria) 


\section{J. Neppert}

\section{Question 1}

I have not treated any patients with AITP with i.v. anti-D Ig.

\section{Question 3}

We hypothesize that it is HLA alloantibodies and not anti-D in anti-D IgG preparations that cause the increase in the platelet count in the treatment of AITP.

There are no other substances present in IgG preparations except HLA antibodies that - even in very low concentrations - can block the Fc-receptors $(\mathrm{FcR})$ of myeloid cells completely [1]. When analyzed by immune phagocytosis inhibition (IPI), this blockade reveals itself to be very selective since no other, non-Fc-receptor-dependent functions of the cells are affected by HLA antibodies, e.g. phagocytosis of foreign particles or Saccharomyces [1]. Therapeutic pooled polyclonal $\mathrm{IgG}$ as well as anti-D IgG induce IPI in vitro [2]. In commercial pooled polyclonal anti-D IgG products, HLA antibodies can be detected by the assay of monoclonal antibody immobilization of platelet antigens using monoclonal antibody w6.32HL [unpubl. data]. We therefore hypothesized a long time ago that the HLA alloantibody-mediated IPI might be the in vivo effect of IgG or anti-D IgG in patients with AITP [2] which results in RES blockade.

This hypothesis is corroborated by evidence that IPI can indeed be induced in vivo. This is derived from the finding that maternal HLA antibodies inhibit the FcR on fetal cells [for a review, see ref. 3]. This may explain why these antibodies are not detrimental to the fetus and why they protect against other detrimental maternal antibodies to various fetal antigens, e.g. Rh and platelet glycoproteins [3].

Thus it was no surprise to find published data indicating a lack of efficacy of monoclonal anti-D in the treatment of AITP and, more importantly, showing the efficacy of polyclonal pooled anti-D IgG in D-negative patients with AITP [4, 5]. Of special interest are D-negative women with AITP who receive anti-D IgG as prophylaxis against $\mathrm{Rh}$ immunization during pregnancy. This treatment can lead to a rise in their platelet count [4] and we would appreciate being informed of any similar cases that may be uncovered through this International Forum so that we can perform a comprehensive survey. To our knowledge, only 2 D-negative patients with
AITP have been successfully treated to date with anti-D $\operatorname{IgG}[4,5]$ and 3 without success [to a review see ref. 4]. But it should be borne in mind that there are always patients who are refractory. The inclusion of these latter patients in any serious argument could only be considered if it were well documented that they showed no refractoriness to high-dosage pooled i.v. $\operatorname{IgG}[6,7]$.

It is not uncommon that therapeutically active substances have side effects. This is a good opportunity to warn against using high amounts of HLA antibodies instead of anti-D. There are 2 instances of both a mild and a lifethreatening interstitial lung edema in healthy subjects subsequent to experimental infusion of a human plasma containing noncytotoxic high-titer anti-HLA DR [Neppert, unpubl. data] and of a preparation of human pooled monocyte-binding IgG [Ouwehand, pers. commun.], respectively. If the HLA alloantibody is the active principle of anti-D IgG, the important questions about the effective vs. dangerous dosis and details about the exact mechanism of effects and side effects still need to be answered.

\section{References}

1 Neppert J: Persistence and selectivity of the immune phagocytosis inhibition by major histocompatibility complex antibodies. Scand J Immunol 1987;26:737-743.

2 Neppert J, Clemens M, Mueller-Eckhardt C: Immune phagocytosis inhibition by commercial immunoglobulins. Blut 1986;52:67-72.

3 Neppert J, Kissel K: Protection against immune haemolytic disease of newborn infants by maternal monocyte-reactive IgG alloantibodies. Lancet 1992;339:1481.

4 Moise KJ, Cano LE, Sala DJ: Resolution of severe thrombocytopenia in a pregnant patient with rhesus-negative blood with autoimmune thrombocytopenic purpura after intravenous rhesus immune globulin. Am J Obstet Gynecol 1990;162:1237-1238.

5 Vizcaino G, Diez-Ewald M, Arteaga-Vizcaino E: Use of anti-D (Rh) IgG or intramuscular polyvalent human immunoglobulin in the treatment of chronic autoimmune thrombocytopenic purpura. Invest Clin 1992;33:165-174.

6 Godeau B, Oksenhendler E, Brossard Y, Bartholeyns J, Leaute J-B, Duedari N, Schaeffer A, Bierling P: Treatment of chronic autoimmune thrombocytopenic purpura with monoclonal anti-D. Transfusion 1996;36:328-330.

7 Neppert J, v. Witzleben-Schürholz E: Treatment of chronic autoimmune thrombocytopenic purpura with monoclonal anti-D: Lack of efficiency due to absence of Fc $\gamma \mathrm{R}$-inhibiting activity? Transfusion 1997;37:444-445.
J. Neppert

Klinikum der Christian-Albrechts

Universität zu Kiel

Institut für Transfusionsmedizin

Michaelistrasse 5

D-24105 Kiel (Germany)

\section{E. Taaning}

\section{Question 1}

In Denmark, we are not treating AITP patients with i.v. anti-D Ig and, to my knowledge, we have never done so in the past.

\section{Question 2}

I do not believe that the $\mathrm{RhD}$ antibodies themselves are involved, but that the increase in platelet count that may occur after treatment is due to other antibodies also present in the i.v. anti-D IgG preparation.

Ellen Taaning

Department of Clinical Immunology and

Blood Bank

Herlev Hospital

DK-2730 Herlev (Denmark)

\section{R. Minchinton}

Our answer from Australia is a simple one. No AITP patient is treated in this way because of our present, severe, chronic shortage of anti-D, even for prophylaxis of haemolytic disease of the newborn. Presently, intravenous gammaglobulin prepared by our own plasma fractionator is used by some clinicians for AITP therapy, and for prophylaxis of FMAIT, but again, national shortages necessitate strict issue guidelines on a case-by-case basis.

Therefore we have no clinical, or laboratory experience of this approach and cannot wisely comment on the remaining questions.

\author{
Robyn Minchinton \\ Chief Scientist \\ Australian Red Cross Blood Service \\ North East Region \\ Queensland Head Office \\ PO Box 10325, Adelaide Street \\ Brisbane, Queensland 4000 (Australia)
}




\section{J.M. Bowman}

For the past $8-10$ years, we have been treating such patients with i.v. anti-D Ig (Win$\mathrm{Rh}_{\mathrm{o}} \mathrm{SD}$ ). We believe, although this is not based on any controlled trial study, that it is some benefit.

The individuals who have the most experience with trials of this treatment are Dr. James Bussel at Cornell University, NewYork Hospital, and Dr. Victor Blanchette at the
Hospital for Sick Children in Toronto. I am sure that you have sent them the same letter.

In respect to the manner in which anti-D causes an increase in platelet count, I would theorize as have others that the increase is related to blockage of Fc receptors by coated Rh-positive red cells. As you are doubtless aware, this treatment is only effective in $\mathrm{Rh}$ positive non-splenectomized individuals.

Although we have no experience with anti-D treatment in Rh-negative patients, we would certainly not expect it to be of any benefit, and also we have no experience with
anti-D treatment of patients with $\operatorname{IgA}$ platelet antibodies.

J.M. Bowman, MD, FRSC

Senior Scholar

Department of Pediatrics \& Child Health

Winnipeg Rh Institute Foundation, Inc.

5th Floor, 735 Notre Dame Ave.

Winnipeg, Manitoba R3E 0L8 (Canada) 